Saudi Journal of Medical and Pharmaceutical Sciences

Abbreviated Key Title: Saudi J Med Pharm Sci ISSN 2413-4929 (Print) |ISSN 2413-4910 (Online) Scholars Middle East Publishers, Dubai, United Arab Emirates Journal homepage: https://saudijournals.com/sjmps

\title{
Characteristics of Ocular Behçet Disease: A Retrospective Study
}

\author{
Imane Chabbar, Bouchra Tamym, Louai Serghini, Abdelkrim Boulanouar, Amina Berraho
}

Ophthalmology B Department, Ibn-Sina University Hospital, Rabat, Morocco

DOI: $10.36348 /$ sjmps.2020.v06i06.011

| Received: 19.06.2020 | Accepted: 26.06.2020 | Published: 30.06 .2020

*Corresponding author: Imane Chabbar

\section{Abstract}

Introduction: Behçet disease is a systemic inflammatory disease characterized by intraocular inflammation, oral and genital ulcers, skin lesions and many other visceral disorders. It is particularly prevalent in the countries of the Mediterranean basin and in the Middle East. The objective of our work is to describe clinical, therapeutic and prognostic characteristics of ocular Behçet disease. Methods: We present a retrospective study of 14 patients with ocular Behçet disease, diagnosed according to the International Study Group of Behçet disease criteria. All patients underwent a complete ophthalmologic examination, Fluorescein Angiography and Optical Coherence Tomography OCT. Results: The average age is 32.5 years, ranging from 17 to 64 years. A male predominance was noted. Visual acuity was > 1/10 in 8 patients, between $1 / 10$ and $5 / 10$ in 4 patients and $>5 / 10$ in 2 patients. Ophthalmological examination revealed an anterior non-granulomatous uveitis in 8 patients, with hypopyon in 2 patients and with acute hypertonia in 2 others, an intermediate uveitis with hyalitis in 2 patients, a retinal vasculitis with periphlebitis in 3 patients, a branch retinal venous occlusion in 1 patient; a macular edema in 2 patients and a papillary edema in 3 patients. Fluorescein Angiography objectified vasculitis with white sheathing end tortuous vessels in 3 cases, peripheral retinal ischemia in 1 patient and papillitis with late diffusion in 3 cases. Macular OCT showed cystoid macular edema in 2 cases. Therapeutic management consisted of topical corticotherapy with mydriatics in isolated anterior inflammation. A bolus of Solumedrol at a dose of $10 \mathrm{mg} / \mathrm{kg} /$ day during 3 followed by an oral relay at $1 \mathrm{mg} / \mathrm{kg} /$ day with progressive degression, was indicated in 8 cases. Retinal photocoagulation was performed in one patient. The evolution was marked by a regression of inflammatory signs with final visual acuity $\leq 1 / 10$ in 4 patients. Two cases were complicated by extended posterior synechiae with acute ocular hypertonia that required a Yag laser iridotomy after inflammation control. Conclusion: Blindness remains the most serious complication of ocular Behçet disease. The prognosis depends on the precocity of treatment and requires a strong collaboration between ophthalmologists and internists.

Keywords: Behçet disease, Retinal vasculitis, Uveitis, Corticotherapy, Immunosuppressive therapy, Blindness.

Copyright @ 2020: This is an open-access article distributed under the terms of the Creative Commons Attribution license which permits unrestricted use, distribution, and reproduction in any medium for non-commercial use (NonCommercial, or CC-BY-NC) provided the original author and source are credited.

\section{INTRODUCTION}

Behçet disease is a multisystemic vasculitis of unknown etiology, characterized by alternating relapses and remissions. One of the major diagnostic criteria is the ocular involvement. It is frequently manifested by panuveitis associated with vasculitis, thus involving the visual prognosis [1]. Blindness remains the most serious complication. The objective of our work is to describe clinical, therapeutic and prognostic characteristics of ocular Behçet disease.

\section{METHODS}

We present a retrospective study of a series of 14 patients with ocular Behçet disease, diagnosed according to the International Study Group of Behçet disease criteria [2]. All patients underwent a complete ophthalmologic examination (AV, slit lamp examination of the anterior segment and fundus with intraocular pressure measurement), Fluorescein Angiography and Optical Coherence Tomography OCT.

\section{RESUlTS}

The average age of our patients is 32.5 years, ranging from 17 to 64 years. A male predominance was noted (10 men and 4 women). Visual acuity (Figure 1) was $>1 / 10$ in 8 patients, between $1 / 10$ and $5 / 10$ in 4 patients and $>5 / 10$ in 2 patients. 


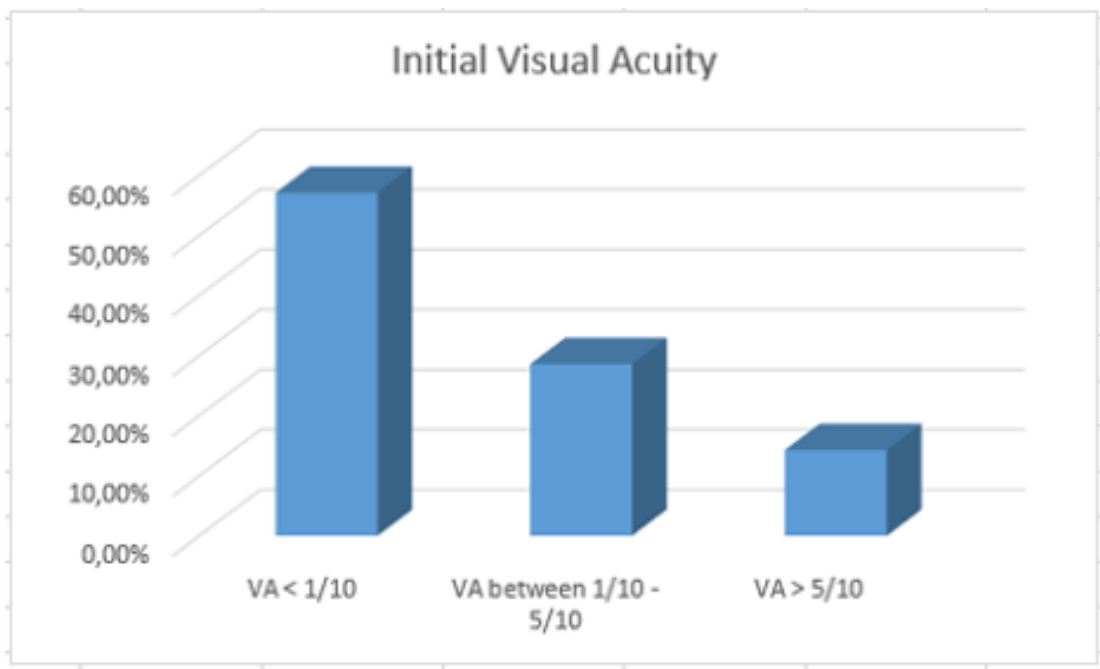

Fig-1: Best corrected visual acuity on admission

The slit lamp examination revealed (Figure-2): an anterior non-granulomatous uveitis in 8 patients, with hypopyon (Figure-3) in 2 patients and with acute hypertonia in 2 others, an intermediate uveitis with hyalitis in 2 patients, a retinal vasculitis with periphlebitis in 3 patients, a branch retinal venous occlusion in 1 patient; a macular edema in 2 patients and a papillary edema in 3 patients.

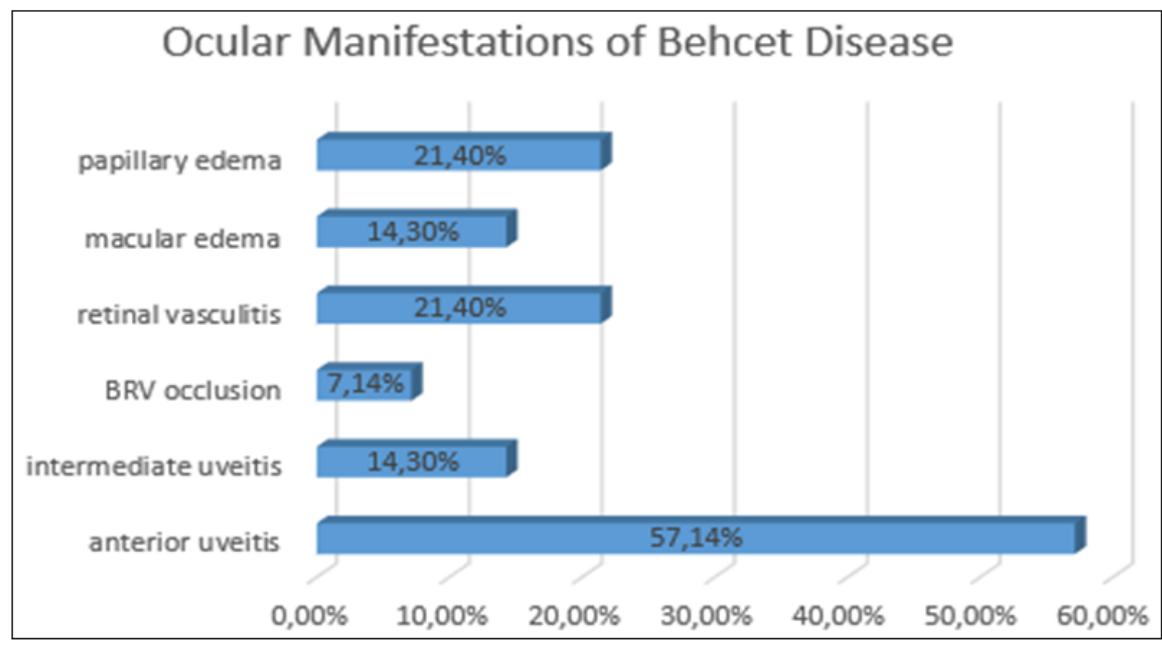

Fig-2: Prevalence of ocular manifestations of Behçet disease in our patients

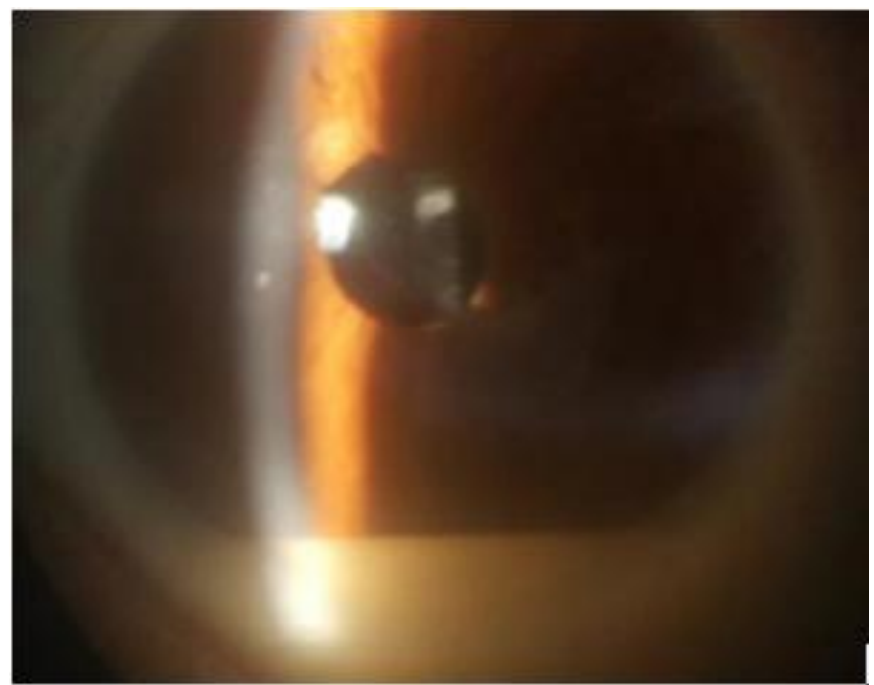

Fig-3: Photo showing an inflammation of anterior chamber with hypopyon 
Imane Chabbar et al; Saudi J Med Pharm Sci, June, 2020; 6(6): 470-473

Fluorescein Angiography (Figures 4 \& 5) objectified vasculitis with white sheathing end tortuous vessels in 3 cases, peripheral retinal ischemia in 1 patient and papillitis with late diffusion in 3 cases.
Macular OCT showed cystoid macular edema in 2 cases (Figure-6) and papillary OCT showed an increased retinal nerve fiber layer in the 3 cases of papillitis.
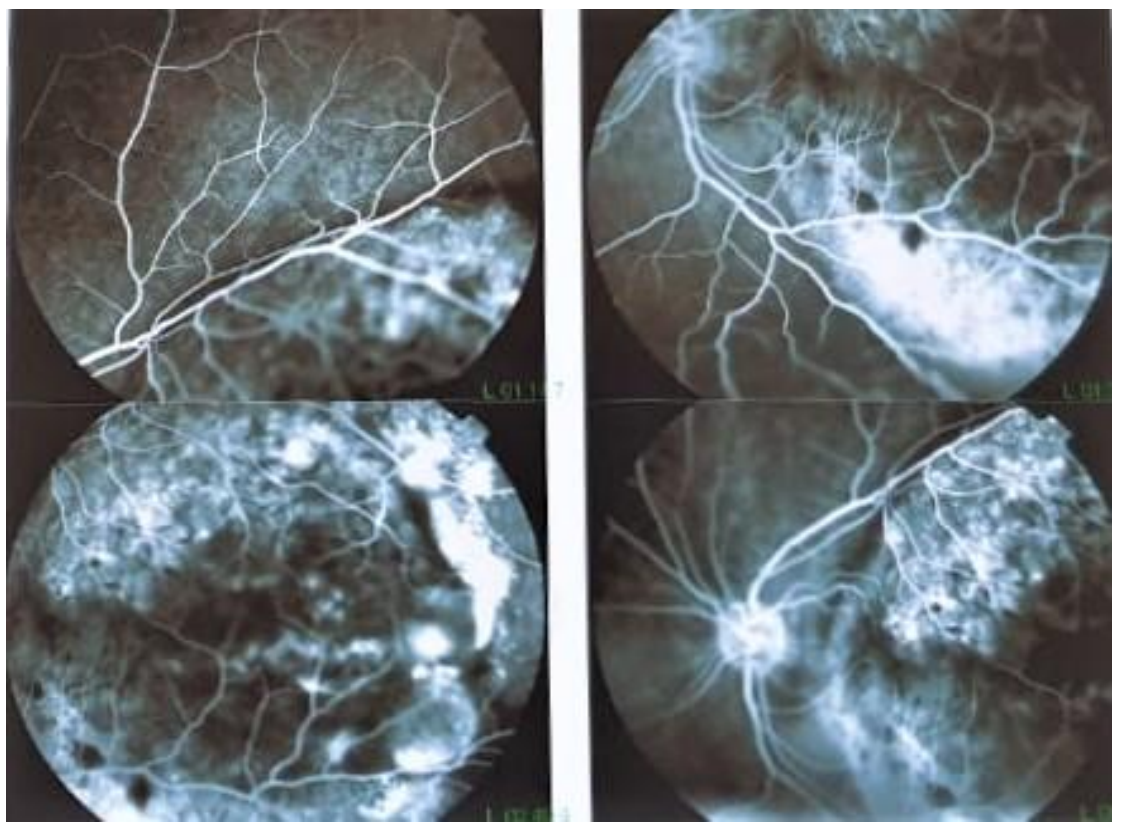

Fig-4: Fluorescein Angiography showing occlusive retinal vasculitis with peripheral retinal ischemia in Behçet disease
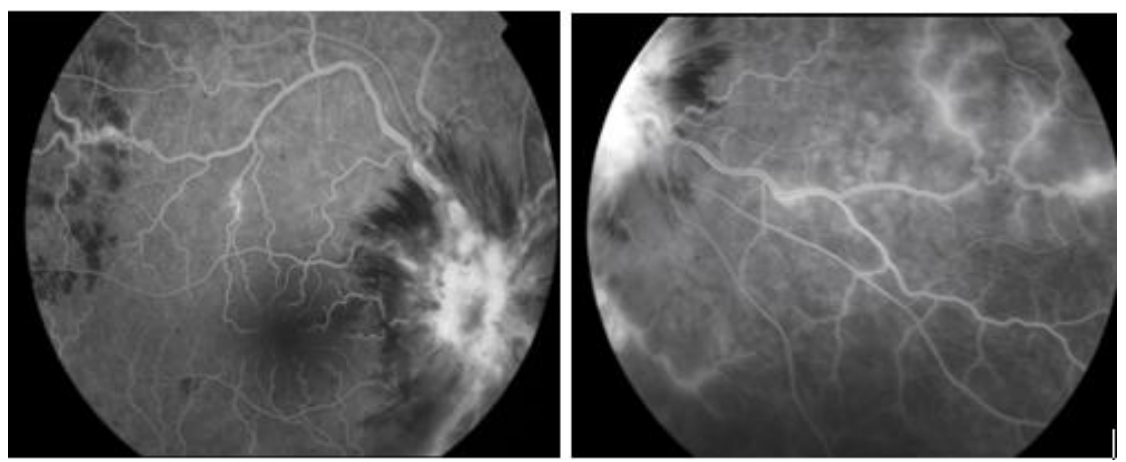

Fig-5: Fluorescein Angiography showing vasculitis with white sheathing end tortuous vessels, and papillitis with peripapillary hemorrhages

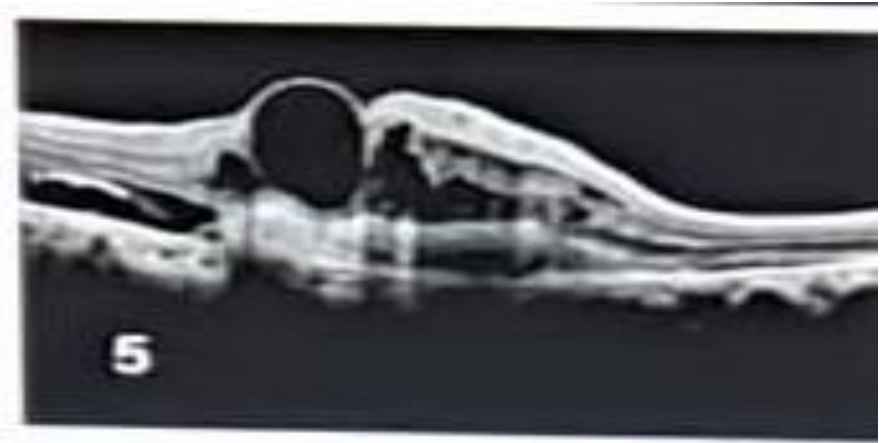

Fig-6: Macular OCT showing cystoid macular edema

Therapeutic management consisted of topical corticotherapy with mydriatics in isolated anterior inflammation. A bolus of Solumedrol at a dose of 10 $\mathrm{mg} / \mathrm{kg} /$ day during 3 followed by an oral relay at $1 \mathrm{mg}$ $/ \mathrm{kg} /$ day with progressive degression, was indicated in 8 cases. Retinal photocoagulation was performed in one patient. The evolution was marked by a regression of inflammatory signs with final visual acuity $\leq 1 / 10$ in 4 patients. Two cases were complicated by extended posterior synechiae (Figure-5) with acute ocular hypertonia that required a Yag laser iridotomy after inflammation control. 


\section{DISCUSSION}

Behçet disease is a systemic inflammatory disease characterized by intraocular inflammation, oral and genital ulcers, skin lesions and many other visceral disorders [1]. It is particularly prevalent in the countries of the Mediterranean basin and in the Middle East [3]. It can affect almost all organs and is currently classified as primary non-necrotizing vasculitis [4]. The male sex is significantly more affected, indeed we noted a male predominance in our series with a sex ratio of 2,5 . The pathophysiological mechanisms evoked in this pathology are complex and involve several probably interlinked factors: genetic factors [5], infectious agents [6], deregulation of the immune system and inflammation mediators $[5,7]$, proteins response to thermal shock, oxidative stress [8], and other environmental factors. In our patients, the diagnosis of Behçet disease is retained according to the criteria of International Study Group of Behçet disease [2] including the presence of recurrent oral ulcers associated with at least two of the following disorders: genital ulcers, inflammatory eye damage, skin damage, positive pathergy test. In terms of ophthalmological involvement, anterior segment lesions are most frequent, but posterior segment lesions are more serious with a poor prognosis [9]. Indeed, anterior uveitis is very suggestive especially if it is associated with a hypopyon but it is neither pathognomonic during Behçet disease. Ocular hypertonia can be linked to trabeculitis, pupillary seclusion or prolonged prescription of corticosteroids. Posterior involvement can be very varied [10], retinal (edema, hemorrhages, exudates, pre-retinal neovessels), papillary (hyperemia, edema), vitreous (hyalitis, PVD, hemorrhages), retinal vasculitis (arterial or venous sheathing, venous dilation, venous occlusion), macular (cystoid macular edema, subretinal neovessels, epi-retinal membrane). Occlusive vasculitis is very characteristic and constitutes an important prognostic element [10]. Classically, blindness occurs in about $50 \%$ of cases within 5 years of the first ocular sign, however, thanks to therapeutic advances in intraocular inflammation management, the visual prognosis has improved remarkably [11]. In our study, visual acuity was limited to counting fingers in $28.5 \%$ of cases. The treatment of Behçet disease is based on corticosteroids and immunosuppressive drugs. Corticosteroids have an immediate anti-inflammatory action on acute attacks, but they must be reinforced by immunosuppressive therapy. The risk of relapse after total or punctual cessation of treatment is possible.

\section{Conclusion}

Behçet disease frequently affects young male patients. The ocular prognosis improved with early management and regular clinical and angiographic monitoring. This prognosis also depends on the precocity of treatment with collaboration between ophthalmologists and internists.

Conflict of interest: The authors declare that they have no conflict of interest.

\section{REFERENCES}

1. Khairallah, M., Kahloun, R., Khairallah-Ksiaa, I., $\&$ Messaoud, R. (2012). The eye and Behçet's disease. Journal francais d'ophtalmologie, 35(10), 826-837.

2. Criteria for diagnosis of Behçet's disease. (1990). International Study Group for Behçet's Disease. Lancet. 335(8697):1078-1080.

3. Chen, K. R., Kawahara, Y., Miyakawa, S., \& Nishikawa, T. (1997). Cutaneous vasculitis in Behcet's disease: a clinical and histopathologic study of 20 patients. Journal of the American Academy of Dermatology, 36(5), 689-696.

4. Zouboulis, C. C., \& Keitel, W. (2002). A historical review of early descriptions of AdamantiadesBehcet's disease. Journal of investigative dermatology, 119(1), 201-205.

5. Zierhut, M., Stübiger, N., Deuter, C., \& Kötter, I. (2005). Behcet's disease. In Uveitis and immunological disorders (pp. 173-200). Springer, Berlin, Heidelberg.

6. Direskeneli, H. (2001). Behcet's disease: infectious aetiology, new autoantigens, and HLAB51. Annals of the rheumatic diseases, 60(11), 996-1002.

7. Salvarani, C., Boiardi, L., Casali, B., Olivieri, I., Ciancio, G., Cantini, F., ... \& Filippini, D. (2002). Endothelial nitric oxide synthase gene polymorphisms in Behçet's disease. The Journal of rheumatology, 29(3), 535-540.

8. Chambers, J. C., Haskard, D. O., \& Kooner, J. S. (2001). Vascular endothelial function and oxidative stress mechanisms in patients with Behçet's syndrome. Journal of the American College of Cardiology, 37(2), 517-520.

9. Razzak, A., Kassimi, A., Mchachi, A., Benhmidoune, L., Chakib, A., Rachid, R., ... \& Elkabli, H. (2019). Eil et Maladie de Behçet: profil épidémiologique, clinique, thérapeutique et évolutif. The Pan African Medical Journal, 33.

10. Atmaca, L. S. (1989). Fundus changes associated with Behçet's disease. Graefe's archive for clinical and experimental ophthalmology,227(4), 340344.

11. Tugal-Tutkun, I., Onal, S., Altan-Yaycioglu, R., Altunbas, H. H., \& Urgancioglu, M. (2004). Uveitis in Behçet disease: an analysis of 880 patients. American journal of ophthalmology, 138(3), 373-380. 